\section{In vitro effect of five pharmaceuticals on the viability of the European abalone hemocytes, Haliotis tuberculata}

\author{
A. Letullier, ${ }^{1,2}$ L. Minguez, ${ }^{1-3}$ K.Costil, ${ }^{1,2}$ \\ M.-P. Halm-Lemeille, ${ }^{1,3}$ J.-M. Lebel, ${ }^{1,2}$
}

A. Serpentini $\mathbf{i}^{1,2}$

${ }^{1}$ Normandie Université, Caen; ${ }^{2}$ UMR BOREA, MNHN, UPMC, UCBN, CNRS7208, IRD-207, Université de Caen Basse-Normandie, SFR ICORE, IBFA, Caen; ${ }^{3}$ Centre d'Etude et de Recherche sur le Médicament de Normandie, UPRES EA-4258, INC3M FR CNRS 3038, Université de Caen Basse-Normandie, SFR ICORE, UFR des Sciences pharmaceutiques, Caen, France

\section{Introduction}

Pharmaceutical compounds are a class of emerging contaminants with potential concern for the aquatic environment. ${ }^{1-3}$ Although they are mainly used for medical and veterinary purposes, their inadvertent release in the environment may pose a potential threat to nontarget aquatic organisms. Pharmaceutical residues are continuously discharged into surface waters and many recent studies have revealed the presence of measurable concentrations from nanogram to low microgram-perliter range. ${ }^{1-2}$ Thus, aquatic organisms are exposed during their entire life cycle and studies are necessary to evaluate their potential effects, particularly on marine organisms for which data are still missing.

The aim of the present study was to investigate the potential effects of four pharmaceutical compounds to Haliotis tuberculata hemocytes in vitro. Hemocytes represent an interesting model due to their key role in defenses of organisms against foreign particles and microorganisms. ${ }^{4,5}$ These cells are routinely used in in vitro ecotoxicological studies for specific endpoints with great precision and reproducibility ${ }^{6-10}$ allowing to chemicallyinduced immunological disorders to be well documented in an increasing number of species. ${ }^{5,11-13}$ Phagocytosis is one of the main immune response and is complemented by an array of bacterial killing mechanisms, where lysosomes are involved. In this study, the four pharmaceutical compounds of interest belong to $\beta$-blockers (acebutolol), antiepileptics (gabapentin), antihistamines (cetirizine) and serotonin-norepinephrine reuptake inhibitors (venlafaxine). Hemocytes were exposed to different concentrations of the selected com- pounds. Toxicities of these different compounds were assessed on the cell viability by the MTT assay and the neutral red uptake assay.

\section{Materials and Methods}

\section{Animals}

Abalones with shell length between 9 and 11 cm were collected by France Haliotis (S. Huchette, Plougerneau, France). Organisms were maintained in natural and continuously aerated seawater at $17^{\circ} \mathrm{C}$ and fed with a mixed algal diet (Laminaria sp. and Palmaria sp.) at the Centre de Recherche en Environnement Côtier (C.R.E.C., Luc-sur-Mer, BasseNormandie, France). Prior their use in our study, abalones were acclimated for at least 2 weeks.

\section{Primary cell cultures}

Hemocytes were cultured as previously described. ${ }^{14}$ Briefly, the hemolymph was collected from the pedal sinus of each abalone with a $20 \mathrm{~mL}$ syringe with a $25 \mathrm{G}$ needle. Hemolymph was transferred into a sterile tube and diluted 1:4 in cooled sterile modified Alsever's solution to avoid hemocyte aggregation. ${ }^{15}$ Cells were rapidly placed into 12 -well plates at a density of $5 \times 10^{5}$ cells per well (MTT assay) or into 24-well plates at a density of $3 \times 10^{5}$ cells per well (neutral red uptake assay) with the addition of three volumes of artificial sterile seawater (ASSW), and maintained at $17^{\circ} \mathrm{C}$ during $90 \mathrm{~min}$. Then, the ASSW were replaced by Hank's sterile 199 medium modified..$^{10,13}$ Cell cultures were incubated at $17^{\circ} \mathrm{C}$ overnight.

\section{Exposure design}

Pharmaceuticals, all supplied by SigmaAldrich at analytical grade were acebutolol ( $\beta$ blocker), cetirizine (antihistamine), gabapentin (antiepileptic), venlafaxine (serotonin-norepinephrine reuptake inhibitor). All pharmaceuticals were dissolved in dimethyl sulfoxide (DMS0) and the final concentration of the solvent was $0.01 \%$. The tested pharmaceutical concentrations ranged from $0.5 \mu \mathrm{g} / \mathrm{L}$ to $500 \mu \mathrm{g} / \mathrm{L}$. Each concentration was tested in quadruplicate (i.e. four wells per concentration). Cells were exposed during $48 \mathrm{~h}$ and the medium was changed every day. The cell exposure was repeated three times, i.e. using three abalones (experiment replicates).

\section{Cytotoxicity assays}

\section{MTT assay}

The effect of pharmaceuticals on hemocytes survival was measured using the MTT reduction assay. ${ }^{16}$ Briefly, $10 \%(\mathrm{v} / \mathrm{v})$ of the MTT stock solution (5 mg MTT/mL PBS 1X) was added to
Correspondence: Antoine Serpentini, UMR BOREA, MNHN, UPMC, UCBN, CNRS-7208, IRD207, Université de Caen Basse-Normandie, Esplanade de la Paix, F-14032 Caen cedex, France.

E-mail: antoine.serpentini@unicaen.fr

Key words: hemocyte, Haliotis tuberculata, pharmaceuticals, in vitro, cell viability.

Conference presentation: ECOBIM meeting, 2014 May, Brest, France.

Acknowledgements: this work is a contribution to the Pharm@Ecotox project funded by the French National Research Agency (ANR, fr: Agence Nationale de la Recherche). This research work was also supported by a post-doctoral grant from the Université de Caen Basse-Normandie (France) to L. Minguez. The authors thank the technical staff of the Centre de Recherche en Environnement Côtier (Luc-sur-Mer, BasseNormandie) for their assistance in animal care.

This work is licensed under a Creative Commons Attribution NonCommercial 3.0 License (CC BYNC 3.0).

(C) Copyright A. Letullier et al., 2014

Licensee PAGEPress, Italy

Journal of Xenobiotics 2014; 4:4900

doi:10.4081/xeno.2014.4900

the culture dishes. After $24 \mathrm{~h}$ incubation at $17^{\circ} \mathrm{C}$, an equal volume of isopropanol containing $0.04 \mathrm{~N} \mathrm{HCl}$ was added to each culture to dissolve the converted formazan dye. The absorbance was measured at a wavelength of $570 \mathrm{~nm}$ with a $630 \mathrm{~nm}$ reference point.

\section{Neutral red uptake assay}

The neutral red uptake assay is a cell viability assay based on the ability of viable cells to incorporate and bind neutral red (NR) within lysosomes. ${ }^{17}$ After treatments, the neutral red uptake assay was used to determine lysosome membrane stability following the method adapted to microplate cultures. ${ }^{10,18}$ Briefly, 30 $\mu \mathrm{L}$ of NR stock solution ( $0.5 \%$ NR in PBS 1X) was added to each well containing $270 \mu \mathrm{L}$ of culture medium. After $1 \mathrm{~h}$ incubation at $17^{\circ} \mathrm{C}$ the medium was removed, and wells were washed first with $3 \%$ formaldehyde in ASSW to fix cells and then twice with PBS 1X. NR was extracted using $1 \%$ glacial acetic acid in 50\% ethanol. After $30 \mathrm{~min}$ at room temperature, the plates were transferred to a TECAN Infinite M200 microplate reader, and the absorbance was measured at a wavelength of $540 \mathrm{~nm}$ with a $650 \mathrm{~nm}$ reference point.

\section{Data analysis}

Results are expressed as means \pm standard deviations (SD). Statistical analyses were undertaken with $\mathrm{R}$ software version 2.15.1, ${ }^{19}$ 
and performed on values resulting from quadruplicate wells containing cells repeated at least three times. Data normality and homoscedasticity were checked but were not assumed even with data transformation. Moreover, as we used pseudoreplication (i.e. the same organism was used to test all the concentrations), the significance of the differences between mean values was estimated using Wilcoxon tests.

\section{Results and Discussion}

The extension of pseudopods by hemocytes and their adhesion capacity play key roles in the cellular migration and the immune defence of mollusks. The morphological results obtained in this study were presented in Figure 1. No morphological changes were observed with increasing pharmaceutical concentrations. Cultured cells displayed an elongated shape with large pseudopods and were mostly interconnected whatever the pharmaceutical tested. Concomitantly, results of MTT assays showed no effects of pharmaceuticals on cell viability under our experimental conditions (data not shown).

In contrast, a significant increase of NR retention was measured for venlafaxine, gabapentin and cetirizine. For venlafaxine and gabapentin, this increased retention was only observed from $250 \mu \mathrm{g} / \mathrm{L}(\mathrm{P}<0.01)$, and can reach $77 \%$ and $50 \%$ of increase at $500 \mu \mathrm{g} / \mathrm{L}$ of venlafaxine (Figure 2A) and Gabapentin (Figure 2B) respectively, compared to control. For Cetirizine (Figure 2C), a significant $(\mathrm{P}<0.05)$ increase of NR uptake by cells was observed when hemocytes were exposed to a concentration of $1 \mu \mathrm{g} / \mathrm{L}$ and reached $85 \%$ of increase compared to the control at $50 \mu \mathrm{g} / \mathrm{L}$. $0 \mathrm{n}$ the contrary, acebutolol (Figure 2D) did not affect NR uptake. Neutral red assays are considered reliable tools to quantify the number of viable and uninjured cells after exposure to pollutants where lysosomal integrity is a generic common target for environmental stressors. ${ }^{20}$ The assay used here is based on the ability of viable cells to uptake the dye and to concentrate it in the lysosomes. Non-viable cells do not take up the dye. A change in the number of cells or in their physiological state related to lysosomes, results in a concomitant change in the amount of dye incorporated by cells. ${ }^{17}$ The abalone hemocytes are not proliferative cells. Thus, the increase of dye incorporation observed in hemocytes exposed to venlafaxine, gabapentin and cetirizine, suggest an increase in lysosome number and/or size. In general, exposure to pollutants is known to cause an increase of lysosomal size which is often linked with a destabilization of lysosomal membranes. ${ }^{21-23}$ These three pharmaceuticals affected the uptake of NR, but displayed different effect profiles. For venlafaxine and gabapentin, the NR uptake was still in the ascending phase of dye accumulation whereas for cetirizine, the maximum accumulation was already observed at $50 \mu \mathrm{g} / \mathrm{L}$ followed by a descending phase of dye accumulation from

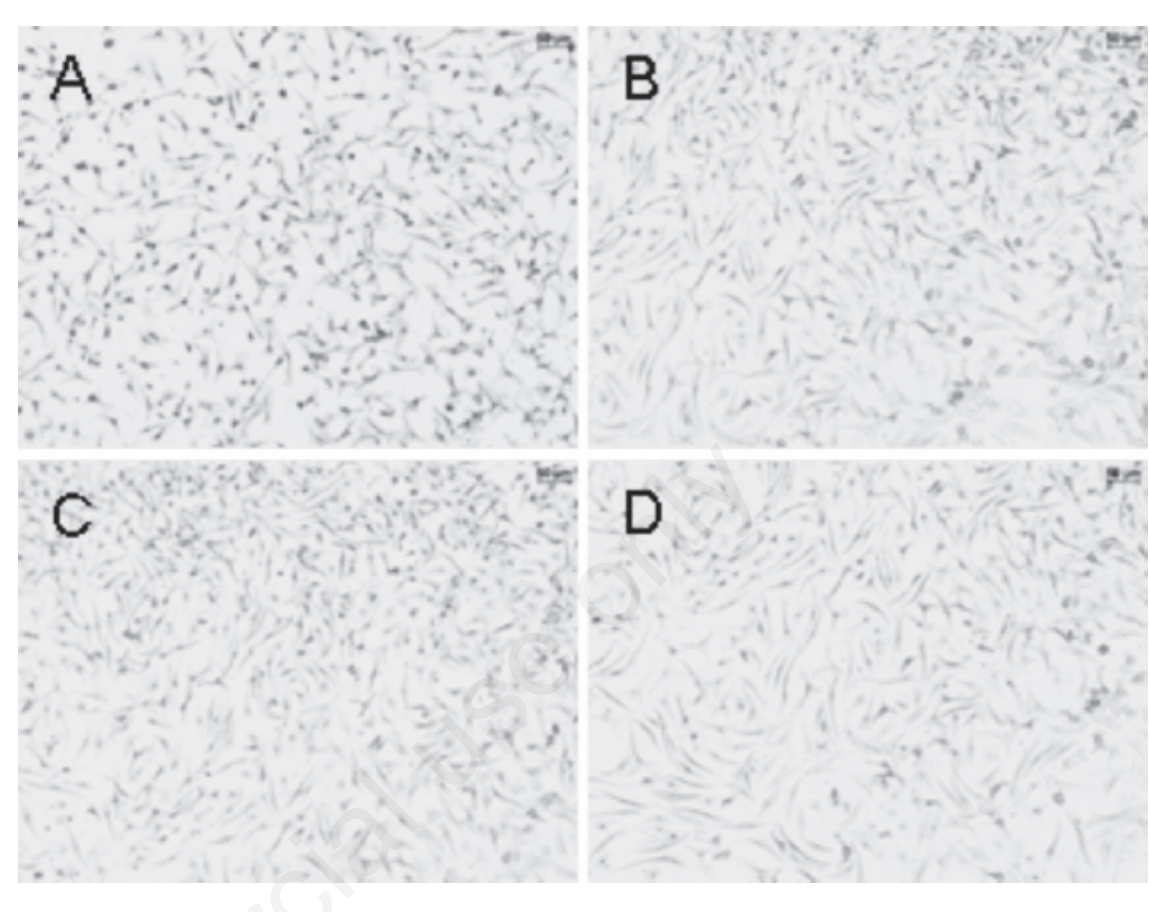

Figure 1. Light microscopy images showing the morphology of Haliotis tuberculata hemocytes. Cells were seeded at a density of $5 \times 105$ cells per well and grown at $17^{\circ} \mathrm{C}$ in culture medium for $48 \mathrm{~h}$ in the absence (A) or presence of $500 \mu \mathrm{g} / \mathrm{L}$ of venlafaxine (B), gabapentine $(C)$ and cetirizine $(D)$.
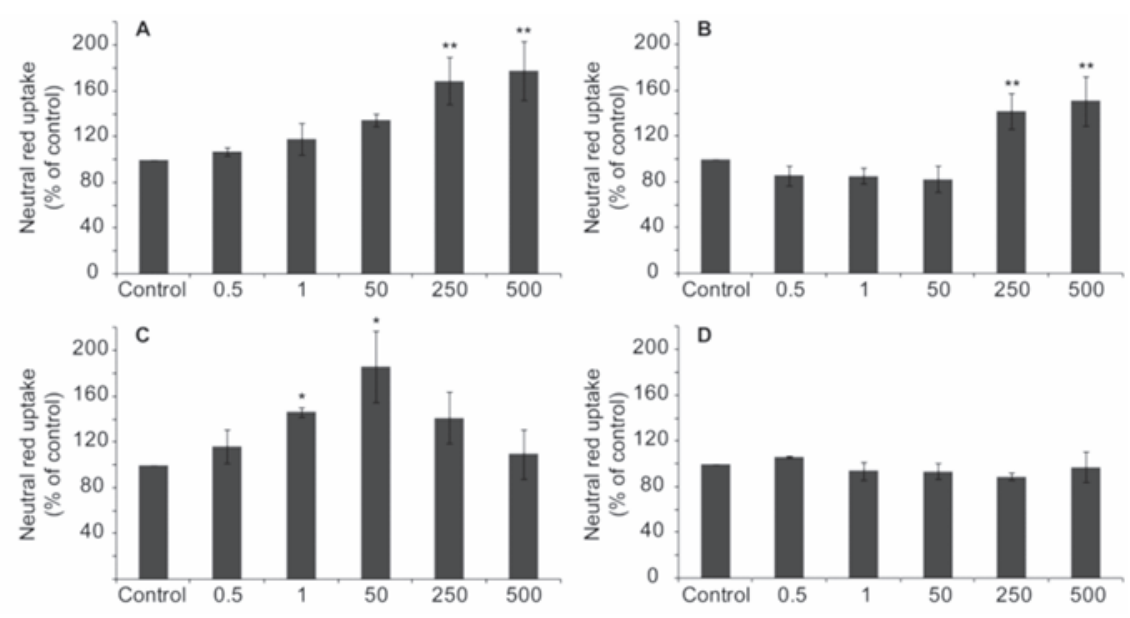

Figure 2. Results of neutral red uptake by control and exposed abalone hemocytes. NR uptake by cells exposed to different concentrations $(\mu \mathrm{g} / \mathrm{L})$ of venlafaxine $(\mathrm{A})$, gabapentine (B), cetirizine (C) or acebutolol (D) were given compared to the $100 \%$ control. Each data point represents the mean percentage $\pm S$.D. of triplicate cultures. Significant differences from control cells were indicated by stars: ${ }^{*} \mathrm{P}<0.05,{ }^{* *} \mathrm{P}<0.01$. 
ity of pharmaceutical mixture on aquatic organisms.

\section{References}

1. Kent K, Weston AA, Caminada D. Ecotoxicology of human pharmaceuticals. Aquat Toxicol 2006;76:122-59.

2. Santos LHMLM, Araújo AN, Fachini A, Pena A, Delerue-Matos C, Montenegro MCBSM. Ecotoxicological aspects related to the presence of pharmaceuticals in the aquatic environment. J Hazard Mater 2010;175: 45-95.

3. Gust M, Fortier M, Garric J, Fournier M, Gagné F. Immunotoxicity of surface waters contaminated by municipal effluents to the snail Lymnaea stagnalis. Aquat Toxicol 2013;126:392-403.

4. Pipe RK, Coles JA. Environmental contaminants influencing immune-function in marine bivalve molluscs. Fish Shellfish Immunol 1995;5:581-95.

5. Auffret M, Rousseau S, Boutet I, Tanguy A, Baron J, Moraga D, et al. A multiparametric approach for monitoring immunotoxic responses in mussels from contaminated sites in western Mediterranean. Ectotoxicol Environ Saf 2006;63:393-405.

6. Brousseau P, Pellerin J, Morin Y, Cyr D, Blakley B, Boermans H, et al. Flow cytometry as a tool to monitor the disturbance of phagocytosis in the clam Mya arenaria hemocytes following in vitro exposure to heavy metals. Toxicology 2000;142:145-56.

7. Sauvé S, Brousseau P, Pellerin J, Morin Y, Senécal L, Goudreau P, et al. Phagocytic activity of marine and freshwater bivalves: in vitro exposure of hemocytes to metals (Ag, Cd, $\mathrm{Hg}$ and $\mathrm{Zn}$ ). Aquat Toxicol 2002;58:189-200.
8. Gagnaire B, Thomas-Guyon H, Renault T. In vitro effects of cadmium and mercury on Pacific oyster, Crassostrea gigas (Thunberg), haemocytes. Fish Shellfish Immunol 2004;16:501-12.

9. Duchemin M, Auffret M, Wessel N, Fortier $\mathrm{M}$, Morin Y, Pellerin J, et al. Multiple experimental approaches of immunotoxic effects of mercury chloride in the blue mussel, Mytilus edulis, through in vivo, in tubo and in vitro exposures. Environ Pollut 2008;153:416-23.

10. Minguez L, Halm-Lemeille MP, Costil K, Bureau R, Lebel JM, Serpentini A. Immunotoxicity assessment of four antidepressants on primary cultures of abalone hemocytes (Haliotis tuberculata). Aquat Toxicol 2014;153:3-11.

11. Gust M, Fortier M, Garric J, Fournier M, Gagné F. Effects of short-term exposure to environmentally relevant concentrations of different pharmaceutical mixtures on the immune response of the pond snail Lymnaea stagnalis. Sci Total Environ 2010;445-446:210-8.

12. Mottin E, Caplat C, Mahaut ML, Costil K, Barillier D, Lebel JM, et al. Effect of in vitro exposure to zinc on immunological parameters of haemocytes from the marine gastropod Haliotis tuberculata. Fish Shellfish Immunol 2010;29:846-53.

13. Latire T, Le Pabic C, Mottin E, Mottier A, Costil K, Koueta N, et al. Responses of primary cultured haemocytes from the marine gastropod Haliotis tuberculata under 10-day exposure to cadmium chloride. Aquat Toxicol 2012;109:213-21.

14. Lebel JM, Giard W, Favrel P, BoucaudCamou E. Effects of different vertebrate growth factors on primary cultures of hemocytes from the gastropod mollusc, Haliotis tuberculata. Biol Cell 1996;86:6772 .
15. Bachère E, Chargot D, Grizel $H$. Separation of Crassostrea gigas hemocytes by density gradient centrifugation and counterflow centrifugal elutriation. Dev Comp Immunol 1988;12:549-59.

16. Mosmann T. Rapid colorimetric assay for cellular growth and survival: application to proliferation and cytotoxicity assays. J Immunol Methods 1983;65:55-63.

17. Repetto G, del Peso A, Zurita JL. Neutral red uptake assay for the estimation of cell viability/cytotoxicity. Nat Protoc 2008;3: 1125-31.

18. Coles JA, Farley SR, Pipe RK. Alteration of the immune response of the common marine mussel Mytilus edulis resulting from exposure to cadmium. Dis Aquat Org 1995;22:59-65.

19. R Core Team. R: A language and environment for statistical computing. Vienna: $\mathbf{R}$ Foundation for Statistical Computing; 2012. Available from: http://www.R-project.org/

20. Viarengo A, Lowe D, Bolognesi C, Fabbri E, Koehler A. The use of biomarkers in biomonitoring: a 2-tier approach assessing the level of pollutant-induced stress syndrome in sentinel organisms. Comp Biochem Physiol C 2007;146:281-300.

21. Moore MN. Lysosomes and environmental stress. Mar Pollut Bull 1982;13:42-3.

22. Etxeberria M, Sastre I, Cajaraville MP, Marigómez I. Digestive lysosome enlargement induced by experimental exposure to metals $(\mathrm{Cu}, \mathrm{Cd}$, and $\mathrm{Zn})$ in mussels collected from a zinc-polluted site. Arch Environ Contam Toxicol 1994;27:338-45.

23.Lowe DM, Fossato VU, Depledge MH. Contaminant-induced lysosomal membrane damage in blood cells of mussels Mytilus galloprovincialis from Venice Lagoon: an in vitro study. Mar Ecol Prog Ser 1995;129:189-96. 